\title{
Kamu Ulaşım Yatırımlarının Taşınmaz Üzerindeki Etkileri: Ordu-Giresun Havalimanı Örneği
}

\author{
Volkan BAŞER ${ }^{1 *}$ \\ ${ }^{1}$ Giresun Üniversitesi, Mühendislik Fakültesi, Harita Mühendisliği Bölümü, Giresun, Türkiye
}

Geliş Tarihi: 19.03.2019

*Sorumlu Yazar: volkan.baser@giresun.edu.tr

Kabul Tarihi: 12.05 .2019

\section{$\ddot{O} z$}

Yeryüzündeki değişik yer şekilleri arasında, doğal ve beşeri etkilere bağlı olarak en hızlı değişime uğrayan alanlar kıyı alanlarıdır. Kıyı ve denizel alanlar her ne kadar tescil dışı alanlar olsa da mühendislik faaliyetlerinin yoğun yaşandığı bölgelerdir. Ülkemizde kıyı ve denizler, kamunun yararlanmasına bırakılmış, Devletin hüküm ve tasarrufu altında olan yerlerdir. Bu alanlar da son zamanlarda kamu yatırımları çok fazla görülmektedir. Kamu yatırımları, ekonomik, sosyal ve kültürel büyümede, istihdam ve yaşam kalitesini arttırmada, insan kaynaklarını geliştirmede, kamu hizmetlerine erişimi ve etkinliği arttırmada önemli katkılar yapmaktadır. Kamu yatırımının yapıldığı bölgede arsa, arazi ve konut gibi gayrimenkullerin değerlerinde artışlar ve çevresinde hızlı şehirleşmeler olmaktadır. Çalışma denizel alan üzerine inşa edilmiş ilk havalimanı olma özelliğini taşıyan, Ordu-Giresun havalimanının mülkiyet kaynaklı toplumsal ve çevresel etkileri üzerinedir. $\mathrm{Bu}$ bağlamda havalimanının çevresindeki taşınmazların değerindeki değişim incelenerek kamu yatırımının etkileri değerlendirilmiştir. Ayrıca artan arazi değerlerinin belirlenmesi ve kamu yatırımının finansmanında kullanılabilirliği üzerine vurgular yapılmıştır.

Anahtar Kelimeler: Arazi Yönetimi, Kamu Yatırımı, Ordu-Giresun Havalimanı, Taşınmaz Değeri

\section{Effects of Public Transportation Investments on Real Estate: Ordu-Giresun Airport Example}

\begin{abstract}
Coastal areas are the fastest-changing areas, depending on natural and human influences, among the different forms of the earth. Coastal and marine areas are areas that are not registered, but where engineering activities are intense. In our country, coasts and seas are places that are left to the benefit of the city and which are under the control and saving of the State. Public investment has been seen in these areas too recently. Public investments, economic, social and cultural growth, as well as improving employment and quality of life, are also making important contributions to improving human resources, increasing access to public services and efficiency. In the region where public investment is made, the values of real estates such as land, land and housing increase and there are rapid urbanization around it. The study is about the social and environmental impacts of the Ordu-Giresun airport, which is the first airport built on a marine area. In this context, the change in the value of the immovable properties around the airport was examined and the effects of public investment were evaluated. In addition, emphasis has been placed on the determination of increased land values and the availability of public investment in financing.
\end{abstract}

Keywords: Land Management, Public Investment, Ordu-Giresun Airport, Real Estate Value 


\section{Giriş}

Toplumun refahı ve kalkınması, kente hızlı erişimin sağlanması için en önemli kamu yatırımlarından biri ulaşım yatırımlarıdır. Bu tür yatırımların etkileri fayda - maliyet analizleri içinde yer almalıdır (Yankaya ve Çelik, 2005). Yer seçiminde, ulaşım altyapısına yönelik herhangi bir yatırımın, kısa dönem içinde taşınmaz değerindeki artış ile karşılanacağı (Alonso, 1964; Muth, 1969; Mills, 1972) test edilmiştir.

Literatür incelendiğinde; Chapman vd. (2009), ABD Utah'daki ulaştırma altyapısının finansmanı için arazi değer vergisinin fizibilitesini incelemiştir. Bu çalışmada istisnai olmayan bir vergi biçimi olmasının yanı sıra arazi değer vergisinden önemli gelir elde edilebileceğini ve idare edilmesinin nispeten kolay olacağını tespit etmiştir. Cohen (2012), Havalimanlarındaki iyileştirmelerin, arazi değerleri üzerinde büyük öneme sahip olacağını vurgulamıştır. Longhofer ve Redfearn (2009) pratikte toprak değerini arazideki yapıların değerinden nasıl ayrılacağını incelemiş ve arazi ile yapıların ayrılmaz olduğunu savunmuştur. Kentin çevresindeki boş araziyi, şehir genelinde arazi değerlerini tahmin etmek için yerel olarak ağırlıklandırılmış regresyonların tahmin tekniği ile birlikte kullanmıştır. Ancak yaklaşımlarının bir dezavantajı, tüm araziler için arazi değerlerini üretirken boş arazi satışlarıyla ilgili verilere ihtiyaç duymalarıdır.

Kamu ulaşım projeleri bölgedeki erişilebilirliği arttırarak bireylerin sosyal hayatına etki etmektedir. Ulaşım alt yapısı sayesinde bölge ekonomisinde gelişmeler olmakta ve çevre, yatırım için cazip hale gelmektedir. Ayrıca zaman tasarrufu, kentsel gelişim, istihdam ve gelir de büyüme, artan erişilebilirlik düzeyi, ulaşım (veya transit) gibi ekonomik etkileri de vardır (Yankaya ve Çelik 2007). $\mathrm{Bu}$ tür yatırımlar ile ulaşım kolaylıkla sağlanabildiği için çevrelerinde yeni konut ve işyeri yatırımları doğmakta, cazip yerleşim alanları oluşabilmektedir. Ulaşım yatırımı sayesinde, taşınmaz değerlerinde, çevrenin sosyal etkinliklere katılımlarında, eğitim ve nüfus verilerinde bazı değişiklikler gözlemlenmektedir (Eryılmaz, 2014).

Türkiye'nin 2023 vizyonu ve hedefleri doğrultusunda ulaşım ve iletişim alanında birçok plan ve projesi bulunmaktadır. Bu projeler parasal olarak milyar dolarlarla ifade edilmektedir. Kentlerin sürdürülebilir ve sağlıklı bir yapıya kavuşturulabilmesi için çevreyi önemseyen ulaşım projelerine ihtiyaç duyulmaktadır. Ülkemizde ulaşım yatırımları, genelde devlet tarafından yapılmakta ve işletilmektedir. Buna karşılık, ulaşım yatırımları ile proje çevresinde oluşan taşınmaz değerlerindeki artıştan kamu yeterince yararlanamamaktadır. Bölgedeki emlak vergi oranları ve yıllık artışları gerçek değerlerden çok aşağıda kalmaktadır. (Eryılmaz, 2014). Ayrıca, bölgedeki arazi spekülasyonları sonucu haksız kazançlar sağlanmaktadır.

Arazi değeri tespitinde birçok kriter göz önünde bulundurulmaktadır. Bunlar, kullanım alanı, manzara, kamu hizmetleri varlığı, gürültü, topografya, merkeze yakınlık gibi faktörlerdir. Örneğin 
kamu yatırımının olduğu bir bölgenin uzağındaki yerleşimlerin erişilebilirliklerinin artması, ulaşım maliyetlerini olumlu yönde etkilemektedir. Bu bağlamda kamu ulaşım yatırımları genellikle arazi satışlarını pozitif etkilemektedir. Kamu ulaşım yatırımlarında arazi maliyeti, güzergâh belirlemede önemli faktörlerden biridir. Çalışma alanı olan Ordu-Giresun havalimanının deniz üzerine yapılma isteğinin (kıyı ve denizler devletin hüküm ve tasarrufu altındadır) en önemli nedenlerinden biri de kamulaştırma maliyetlerini ortadan kaldırmaktır.

\section{2. Çalışmanın Amacı ve Kapsam}

Çalışmanın amacı, kamu ulaşım projelerinin yapıldığı çevrede oluşan, arazi değer değişimlerinin incelenmesidir. Ayrıca ulaşım yatırımları sonucu artan arazi değerlerinden kamunun yararlandırılıp yararlandırılamayacağı üzerinedir. Bu amaçla, 2011 yılında yapımına başlanan ve 2015 yılında hizmete açılan Ordu - Giresun Havalimanın çevresindeki arazi değerleri için taşınmaz alım/satımı yapan emlakçılarla görüşmeler yapılmış ve veriler toplanmaya çalışılmıştır. Ayrıca, Gelirler İdaresi Başkanlığı'nca dört yılda bir güncellenerek yayımlanan “Arsa ve Arazi Birim Metrekare Değerleri” veri olarak kullanılmıştır.

\section{3. Çalışma Alanı}

Ordu-Giresun Havalimanı Ordu il merkezine 17 km, Giresun il merkezine 28 km uzaklıkta olup, coğrafi konumu 40 57' 53" Kuzey enlemi ile 38 4' 48" Doğu boylamındadır. Havalimanı Ordu ili Gülyalı ilçe merkezinin kıyısında denizden kazanılmış arazi üzerine inşa edilmiştir (Şekil 1). Gülyalı'nın doğusunda ilçeye 6 km mesafede olan Piraziz, Giresun ilinin havalimanına en yakın konumdaki ilçesidir. Aynı zamanda bu ilçe havalimanına yakın konumuyla, bir ulaşım sistemi olarak düşünüldüğünde havayolu ulaşımının avantajlarından en fazla faydalanacak alanların başında gelir. Her iki ile hizmet etmesi amacıyla Ordu ve Giresun'un birbirine yakın kesiminde inşa edilen havalimanının doğusu Piraziz, batısı Altınordu, kuzeyi Karadeniz ve güneyi Gülyalı ile çevrilidir. Havalimanının güneydeki uzak komşuları ise Tokat, Sivas ve Gümüşhane illeridir. Havalimanının Giresun ilinin en doğudaki ilçesi durumunda olan Eynesil'e uzaklığg 103 km'dir. Ayrıca havalimanı batısındaki Altınordu' ya 14 km, Ordu ilinin batıdaki en uç noktası olan Ünye’ye ise 78 km uzaklıktadır.

Ordu-Giresun havalimanı Türkiye'de deniz üzerine yapılmış ilk havalimanıdır. 1970'li y1llardan beri yapılması planlanan fakat bürokratik sebeplerle ancak yapımına 2011 y1lında başlanmıştır. Havalimanı 2015 yılında yapımı tamamlanarak hizmete açılmıştır. 


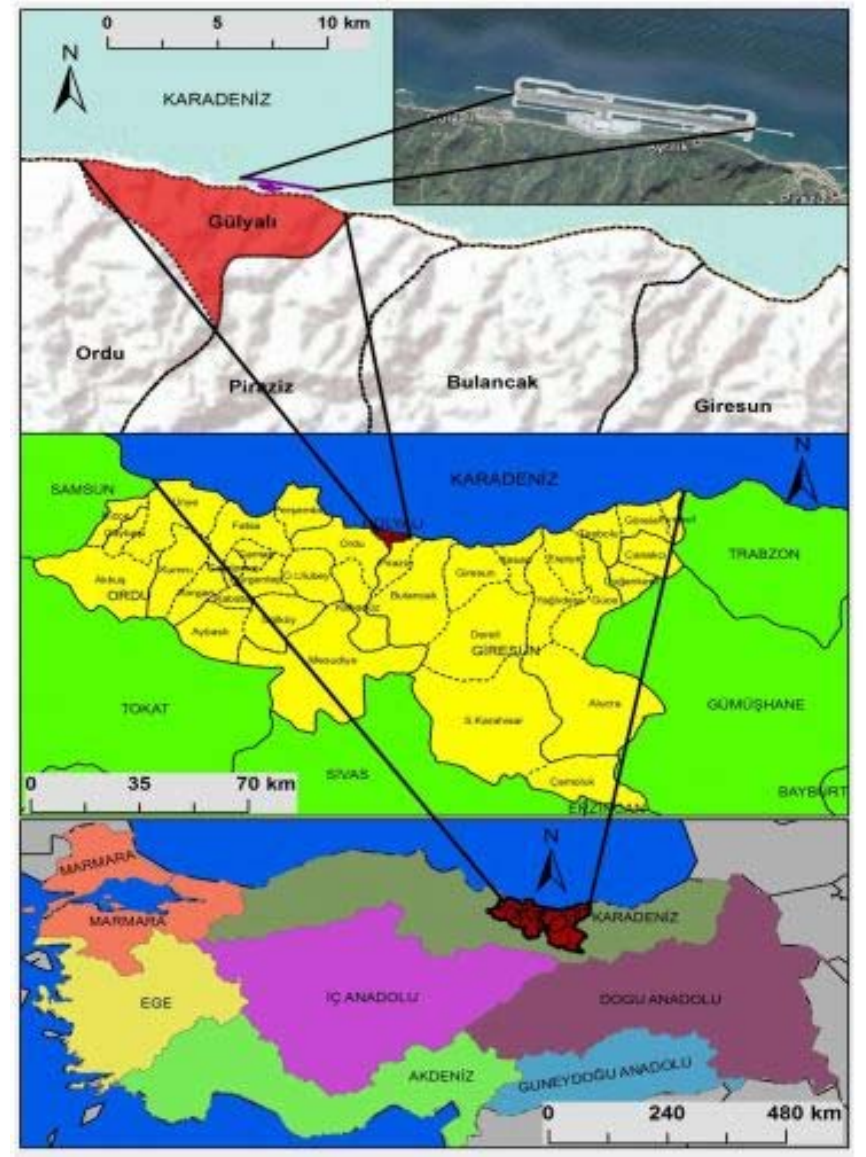

Şekil 1. Çalışma Alanı Haritası (Türk, 2015).

\section{Kamu Ulaşım Yatırımlarının Taşınmaz Üzerindeki Etkileri}

Kamu ulaşım yatırımları bölgenin arazi kullanım, taşınmaz değer, eğitim ve nüfus yapısında (gelirler, iş dağılımı ve ulaşım biçimleri de dâhil olmak üzere) belirli oranlarda etkilerde bulunmaktadir.

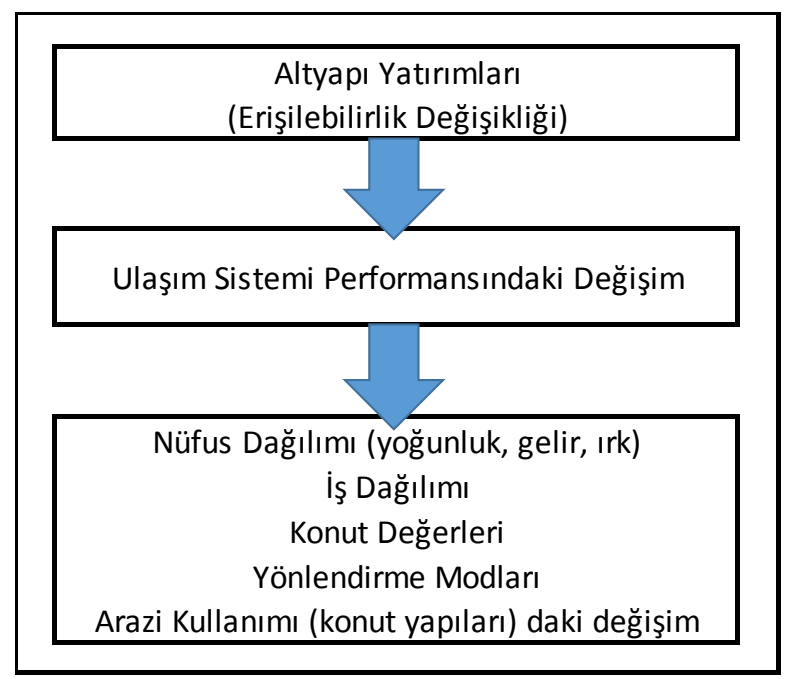

Şekil 2. Arazi kullanımı ve nüfus üzerine etkiler (Trinidad, 2017). 


\subsection{Ekonomik Etkiler}

Ordu ve Giresun ülkemizde nüfus hareketliliğinin yoğun olduğu yerlerdendir. Ordu ve Giresun il nüfusuna kayıtlı birçok insan kendi memleketlerinden uzakta, belli bir kısmı da ülke dışında yaşamaktadır. Bu insanların büyük bir kısmı yılın belli dönemlerinde memleketlerine gelip-gitmek istediklerinde zorunlu olarak karayolu ulaşımını kullanmaktadırlar. Havalimanı ile bu durum azalacaktır. Havalimanının varlığı bölgenin en önemli geçim kaynağı olan fındığın pazarlanmasına önemli ölçüde katkı sağlayacaktır (Türk, 2015). Sanayi, ticaret ve ulaşım sektörleri birbirinden bağımsız düşünülemeyeceğinden doğrudan bir etki yaratmasa da havalimanının varlığının bölge sanayisinin gelişimine de katkı sağlayacaktır. Ayrıca çevre illerdeki turizm gelişsimi değerlendirildiğinde havalimanının turizm ve eğitim üzerinde de olumlu etkileri olacaktır.

\subsection{Kentsel Planlamaya Olan Etkiler}

Şehirler, insanların ve işletmelerin merkezden uzaklaşması, artan banliyösüzleşme ve daha düşük konut ve iş yoğunluğu arzusu ile değişmektedir. Şehirlerden çıkış, kısmen şehir merkezlerinde uygun fiyatlı konut eksikliği ve daha fazla alan arzusundan kaynaklanmaktadır. Yeni talebi karşılamak için yeni yollara yatırım yapmak gerekecektir. Bu bağlamda ulaşım yatırımlarının şehirlerin ve bölgelerin konumsal ve ekonomik gelişimine katkısı büyüktür. Bazı bölgelerin cazibesi erişilebilirliği ile doğru orantılıdır bu da ulaşım altyapısının kalitesi ve sağlamlığına bağlıdır.

Ulaşım maliyeti, yatırım kararları için öncelikli kriterlerdendir. Ulaşım altyapısı, endüstri, alışveriş merkezi ve konut alanlarının yapımı gibi yatırımların planlanmasında temel unsurdur. Çünkü şehir ulaşım kararları ile şekillenecektir. Bu bağlamda çalışma alanında bulunan Ordu-Giresun Havalimanı 1.770.000 $\mathrm{m}^{2}$ büyüklüğünde deniz dolgusu üzerine inşa edildiği için bölgedeki mevcut arazi üzerinde bir alan işgal etmemektedir. Havalimanının çevresinde yapacağı çekim kuvveti bölgedeki yapılaşmayı ve kentleşmeyi etkileyecektir. Bölgede havalimanı yapımı ile Gülyalı ve Piraziz belediyelerine yapılan arsa ve işyeri ruhsatı taleplerinde artışlar meydana gelmiştir (Türk 2015). Ayrıca havalimanının faaliyete geçmesiyle, havalimanına komşu illerde yabancı yatırımcı ilgisi artmıştır.

\subsection{Turizm Etkileri}

Ordu ve Giresun'un turizm açısından istenilen ölçüde tanınır olmayışının nedenleri arasında, bölgedeki turistik alanlarının yeteri kadar tanınmaması ve bölgeye hızlıca erişimi sağlayacak bir ulaşım ağının yeni yeni oluşması gösterilebilir. Havalimanının faaliyete geçmesiyle bu olumsuz 
durum değişecektir. Şöyle ki Trabzon havalimanı incelendiğinde sadece dış hatlar bazında yaz aylarında yabancı turist akını olduğu gözlenmekte olup (Şekil 3), bu yoğunluk bölgede büyük bir ekonomik değişime neden olmaktadır.

\begin{tabular}{|c|c|c|c|c|}
\hline \multicolumn{5}{|c|}{$\begin{array}{l}\text { TRABZON HAVALIMMANI } \\
\text { Diş Hatlar Geliş }\end{array}$} \\
\hline \multicolumn{5}{|c|}{ 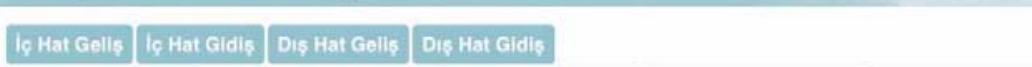 } \\
\hline Tarih & Havayolu & Uçuş No & Geldiği Yer & Planlanan \\
\hline Date & Airline & Flight No & Origin & Sch.Time \\
\hline 17.08.2017 & ruenaramume 0 & TK 1193 & Yanbo & $16: 30$ \\
\hline 17.08.2017 & Aairarabia & G9 285 & Sharjah & $18: 40$ \\
\hline 17.08.2017 & ruexsun namuses 0 & TK 1283 & Kuveyt & $21: 55$ \\
\hline 18.08.2017 & 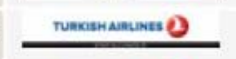 & TK 1191 & Medine & $02: 15$ \\
\hline 18.08.2017 & runasumamumes 0 & TK 1740 & Berlin & 02:20 \\
\hline 18.08.2017 & PEGASUS & PC 1594 & Koln & $02: 20$ \\
\hline 18.08.2017 & 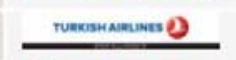 & TK 1714 & Stuttgart & $02: 40$ \\
\hline 18.08.2017 & (A) atlasglobal & KK 8851 & Riyadh & 06:35 \\
\hline 18.08.2017 & Nenosumanas 0 & TK 5879 & Medine & $10: 10$ \\
\hline 18.08.2017 & ruensumamense 0 & TK 231 & Jeddah & $13: 30$ \\
\hline
\end{tabular}

Şekil 3. Trabzon havalimanı 17-18 Ağustos 2017 dış hat gelen direkt uçak (URL-2).

Trabzon Ticaret ve Sanayi Odası (TTSO) Başkanı, “Türkiye genelinde inşaat sektöründe 2017 yılı Mayıs ayı itibarıla ilk el satışlarda yüzde 5.5 düşüş olduğunu, İkinci el satışlarda ise yüzde 8.5 civarında artış olduğunu vurgulamaktadır. Yabancıya konut satışlarında ise yüzde 10 civarında artışın olduğunu belirterek Trabzon'un 2017 Mayıs ayı itibarıla Türkiye'de yabancıya konut satışları yönünden üçüncü sırada bulunduğunu ve daha fazla tercih edilmeye başlandığını ifade etmektedir" (URL - 1). Diğer taraftan Türkiye'den konut satın alan yabancı ülke vatandaşları sırasıyla Suudi Arabistan, Irak, Rusya Federasyonu, Kuveyt ve Afganistan'dır (URL - 1). Bu bağlamda yabancılara konut satma düşüncesinde olan firmalar bu ülke sıralamasını göz önünde bulundurmalıdırlar.

Trabzon ve çevresindeki yabancı turist sayısındaki yoğunluğun en önemli nedenlerinin başında Trabzon havalimanı gelmektedir. Ordu - Giresun havalimanını zamanla faaliyetlerini artırması Trabzon ve çevresindeki yabancı turist yoğunluğunun bu bölgelere doğru kayabileceğini göstermektedir. $\mathrm{Bu}$ değişimin söylentileri bile taşınmaz değerleri üzerinde pozitif bir etki yapmaktadir. 


\subsection{Taşınmaz Değerine Etkiler}

Taşınmaz piyasasında ulaşım yatırımının yararları ekonomik olarak değerlendirilmektedir. Ulaşım yatırımından kaynaklanan erişilebilirlik düzeyindeki artış ve kentsel bölgenin geri kalan kısmı ile iyi kurulan bağlantı yatırıma değer katmaktadır (Erdem, 2016). Bu hizmetten yararlanan arsaların firma ve konut birimleri için çekiciliği artacaktır. Bu yatırımların etkileri; sanayi, ticaret, ofis veya konut birimlerinin satış veya kira fiyatlarındaki değişimler üzerinden ölçülebilir (Yankaya ve Çelik 2007).

Taşınmaz alım-satım fiyatlarının bildiriminde zorunluluk bulunmaması, vergi oranlarının algılanış biçimi, ticari gizliliğin sağlanması gibi sebepler sağlıklı bir veri tabanı kurulumunu engellemektedir. (Eryılmaz 2014). Bu durum bilimsel karar verme mekanizmalarını minimize etmektedir. Kamu kararlarını hesap vermekten uzak kurgulamakta ve kentsel planlamadan çok fiziksel planlama ile sınırlandırmaktadır.

Ordu-Giresun havalimanı yatırımı ile büyük bir değişime uğrayan çalışma bölgesine ilişkin olarak iki şekilde veri toplanmıştır. Birincisi Gelirler İdaresi Başkanlığının 4 yılda bir yayımladığı asgari $\mathrm{m} 2$ birim değerleri, ikincisi ise bölgede alım-satım yapan emlakçılardan toplanana rayiç bedellerdir.

1. Tip veriler: Maliye Bakanlığg Gelir İdaresi Başkanlığınca dört yılda bir yayımlanan ve her y1l belli oranlarda arttırılan “Arsa ve Arazi Asgari Birim Metrekare Değerleri” verilerini içermektedir. Bunlar 2009 yılından itibaren belirlenmiş vergi değerleridir. 2009, 2013, 2017 yıllarına ait birim metrekaredeki değerler incelenerek değişim belirlenmeye çalışılmıştır.

2. Tip veriler: Bölgedeki parsellerin alım-satım değerlerinin elde edilmesinde doğru sonuca en yakın veriyi tespit edebilmek için uygulama bölgesinde yaşayan insanlardan, bölge emlakçılarından ve bu bölgede çalışma yapan müteahhitlerden faydalanılmıştır. Alım-satım bedeli olarak bu değerlerin ortalaması kullanılmıştır.

Gülistan Mah. Ordu ilinde yer almakta olup, Gülyalı Merkez semtinde bulunan Gülistan Mah. Gülyalı ilçesine bağlıdır. Gülistan Mah. haritası konumu ise $40^{\circ} 58^{\prime} 0.5664^{\prime \prime}$ Kuzey ve 38 3' 22.4640" Doğu, GPS koordinatlarıdır. Gülistan Mah. bağlı olduğu Gülyalı ilçe merkezine çok yakındır. Gülistan Mah. Ordu şehir merkezine mesafesi ise yaklaşık 15 kilometredir. 


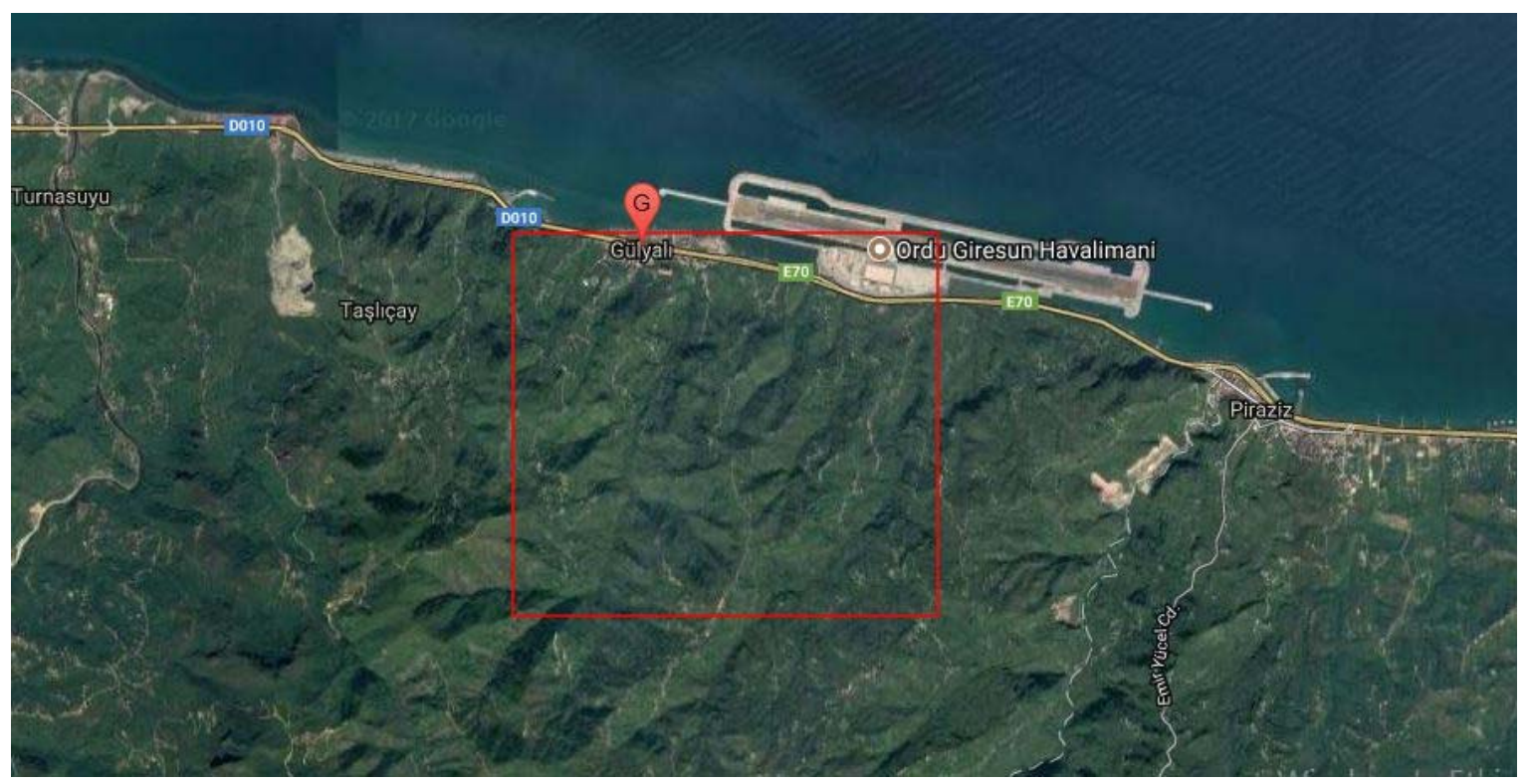

Şekil 4. Ordu ili Gülyalı İlçesi Gülistan Mahallesi.

Tablo 1. Gülyalı İlçesi Gülistan Mahallesi Değer Takdir Komisyon ve Piyasa Rayiç Değerleri.

\begin{tabular}{|c|c|c|c|c|c|c|c|}
\hline \multirow{2}{*}{$\begin{array}{l}\text { Sira } \\
\text { No }\end{array}$} & \multirow{2}{*}{ Mevkii } & \multirow{2}{*}{$\begin{array}{l}\text { Cadde/ } \\
\text { Sokak }\end{array}$} & \multirow{2}{*}{ Pafta } & \multicolumn{3}{|c|}{ Takdir Olunan Değer (m2/TL) } & \multirow{2}{*}{$\begin{array}{c}\text { Rayiç } \\
\text { Değerler } \\
\text { (m2/TL) }\end{array}$} \\
\hline & & & & 27.7.2009 & 7.5.2013 & 18.5.2017 & \\
\hline 1 & $\begin{array}{l}\text { ERSİN TARANOĞLU } \\
\text { CADDESİ (Sahil Kısım) }\end{array}$ & $\mathrm{C}$ & $1-2-3-4$ & 90.00 & 117.00 & 250.00 & 840.00 \\
\hline 2 & $\begin{array}{l}\text { ERSİN TARANOĞLU } \\
\text { CADDESİ (İç Kısım) }\end{array}$ & $\mathrm{C}$ & $1-2-3-4$ & 40.00 & 52.00 & 100.00 & 347.00 \\
\hline 3 & ORDU CADDESİ & $\mathrm{C}$ & $1-2-3-4$ & 90.00 & 117.00 & 250.00 & 790.00 \\
\hline 4 & $\begin{array}{l}\text { EMINOĞLU CADDESİ } \\
\text { (Sahil Mevkii) }\end{array}$ & $\mathrm{C}$ & $1-2-3-4$ & 90.00 & 117.00 & 200.00 & 560.00 \\
\hline 5 & $\begin{array}{l}\text { EMİNOĞLU CADDESİ } \\
\text { (Köseoğlu Mevkii) }\end{array}$ & $\mathrm{C}$ & $6-7-8-14$ & 30.00 & 39.00 & 100.00 & 310.00 \\
\hline 6 & $\begin{array}{l}\text { EMİNOĞLU CADDESİ } \\
\text { (Türkmenli Mevkii) }\end{array}$ & $\mathrm{C}$ & $6-7-8-14$ & 20.00 & 26.00 & 50.00 & 220.00 \\
\hline 7 & SAKAOĞLU CADDESİ & $\mathrm{C}$ & $5-6-7-8$ & 20.00 & 26.00 & 50.00 & 200.00 \\
\hline 8 & $\begin{array}{l}\text { GÜLİSTAN CADDESİ } \\
\text { (Çakmaklar Mevkii) }\end{array}$ & $\mathrm{C}$ & $1-2-3-4$ & 40.00 & 52.00 & 100.00 & 320.00 \\
\hline 9 & USTALI CADDESİ & $\mathrm{C}$ & $6-7-8-14$ & 30.00 & 39.00 & 50.00 & 210.00 \\
\hline
\end{tabular}

Belirlenen bölgeye ait yıllara göre değer takdir komisyonlarınca belirlenmiş değerler ve rayiç bedellerden oluşan değişimin gösterimi aşağıda şekil 5'te verilmiştir. 


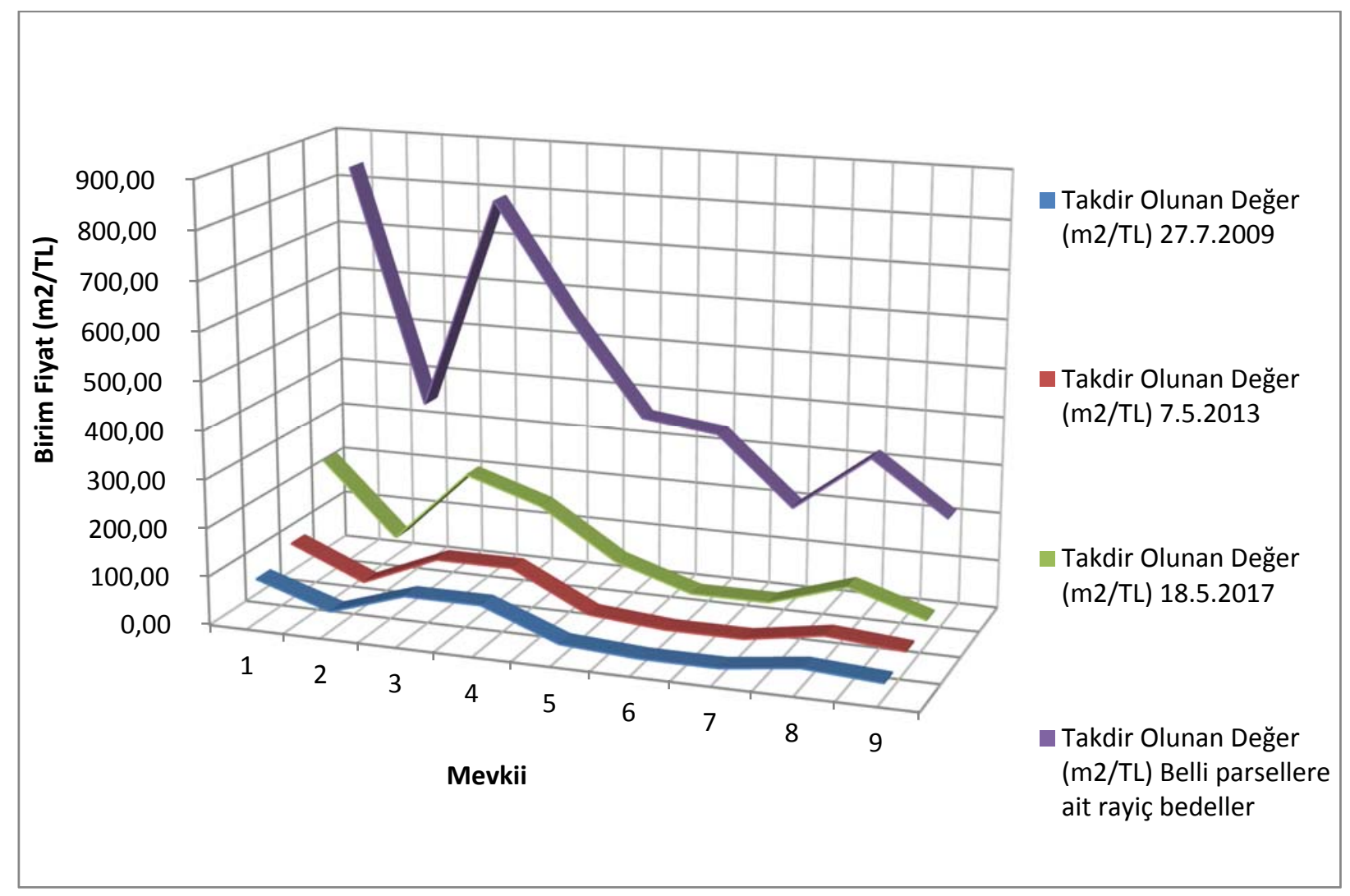

Şekil 5. Yıllara göre değer takdir komisyonları ve rayiç bedeller.

Şekil 5 ve tablo 1 incelendiğinde görülmektedir ki Gülyalı ilçesi Gülistan Mahallesinde değer takdir komisyonlarınca belirlenmiş yıllara göre oluşan değer değişimi 2009-2013 yılları arasında yaklaşık \%30 civarında artma eğilimi göstermekte iken 2013-2017 yılları arasındaki taşınmaz değerindeki artış \%100'ü bulmuş ve hatta geçmiştir. Ayrıca güllük alım satım bedellerinde bu değişim \%400 gibi değerlere ulaşmıştır. Ordu - Giresun Havalimanının hizmete girdiği 2015 tarihi göz önüne alındığında bölgede kamu yatırımıyla taşınmazlarda oluşan değer değişimi (pozitif yönde) açıkça gözlemlenmektedir.

\section{Kamu Yatırımlarının Vergilendirilmesi (KYV)}

İyi bir planlama şehirlerin büyümesi için en önemli kriterdir. Şehirlerin büyümesi altyap1 ihtiyacını arttırmakta ve kamusal kaynaklarda azalmaya neden olmaktadır. Yapılan kamu yatırımları ve imar planı değişiklikleri ile kişilerin mülklerinde önemli ölçüde değer artışları olmaktadır.

Türkiye'de değer artışları;

- 193 Sayılı Gelir Vergisi Kanunu’nda değer artış kazançları,

- 3194 Sayılı İmar Kanunu'nda düzenleme ortaklık payı,

- 2464 Sayılı Belediye Gelirleri Kanunu'nda harcamalara katılım payları rant vergileri (Aslan, 2014) şeklindedir. 
$\mathrm{Bu}$ düzenlemelere rağmen, kentsel rantların tamamı vergilendirilememiştir. Mülga 5237 sayılı eski belediye gelirler yasasının 16. Maddesinde önemli bir gelir vergisi olarak düşünülebilecek şerefiye açık anlamı ile belirtilmiştir. Uluslararası literatürde şerefiye uygulamalarına benzer vergi biçimleri tartışılmakta ve uygulanmaktadır. Ancak gelişmiş bazı ülkelerde çeşitli uygulamaları olmasına rağmen ülkemizde şerefiye uygulaması 2464 sayılı yeni belediye gelirler yasasında kaldırılmıştır. Bu tür bir gelir vergisi kamu yatırımı ile oluşan arazi değer artışını yakalama yöntemi olarak düşünülmelidir (Baser et al., 2019).

\section{Tartışma ve Sonuçlar}

Kamu yatırımları bulundukları bölgelerde taşınmaz fiyatlarını hızla arttırmakta ve ekonomik hayatı etkilemektedir. Ulaşım ve istihdam olanaklarının kolaylaştııılması ile taşınmazlarda oluşan değer artışlarından toprak sahipleri ve ev sahipleri sıklıkla yararlanmaktadır. Bu nedenledir ki altyapı iyileştirme maliyetlerinden daha fazla pay almak gerekir. Dahası, ulaşım altyapısı ile oluşacak değeri yakalama, ilave altyapıyı finanse etmek için kullanılabilecek gelirleri artırma potansiyeline sahiptir. Doğru şekilde yapılırsa, değer yakalama da verimliliği tehlikeye atmayacaktır. Gelir tahsisi açısından etkin ve verimli bir vergi ve kaçınılmaz olan vergiyi uygulamak için yöntem olarak, arazi değerini yakalama yöntemi önemli bir yaklaşımdır (Cohen, 2012).

Chapman ve ark. (2009), ABD Utah'daki ulaştırma altyapısının finansmanı için arazi değer vergisinin fizibilitesini incelemişlerdir. Bu çalışmada istisnai olmayan bir vergi biçimi olmasının yanı sıra arazi değer vergisinden önemli gelir elde edilebileceğini ve idare edilmesinin nispeten kolay olacağını tespit etmişlerdir. Bu bağlamda mevcut ekonomik ve siyasi çerçevede büyük ulaşım altyapı projelerine finansman sağlamak oldukça zordur. İlave düşünülmesi gereken umut verici bir finansman seçeneği, altyapı projesiyle ilişkili arazi değer artışının yakalanması ve bir kısmının kamuya geri kazandırılmasıdır. Yatırımın yapıldığı bölgedeki mevcut parsellerde bir değer artış1 oluştuğu aşikârdır. Bu değer artışından sadece parsel sahiplerini değil, aynı zamanda uygulamayı gerçekleştirecek kurumun da faydalanması doğru olacaktır.

Bir arazi değer vergisinin uygulanmasına ilişkin olarak, siyasi ve ekonomik iki konu önemlidir. Siyasi olarak, vergi konusunda politik destek sağlayan bir tabanın geliştirilmesi ve korunması gerektiğidir; ekonomik olarak ise, güvenilir, piyasa temelli değerlendirmelerin zamanında üretilmesidir. Dolayısıyla, odak noktamız arazi değer vergisinin uygulanması değil, güvenilir tahminler sunma ve toprak değer vergilendirmesi için bu temel bileşeni üretmek olmalıdır. Altyapının arazi fiyatları üzerindeki etkisinin doğru bir tahmini çok önemlidir. Arazi değerini zaman içerisinde etkileyebilecek faktörler değerlendirilip çıkarıldıktan sonra, havalimanı gibi ulaşım altyapılarının 
taşınmazlar üzerindeki değer artışı belirlenebilir. Yerel yönetimler, gelişmiş havaalanı altyapısının oluşturduğu değer artışına dayanarak araziye vergi yükleyebilirler.

Çalışma bölgesi incelendiğinde ulaştırma yatırımlarının bölgedeki arazilerde önemli değer artışlarına neden olduğu gözlemlenmiştir. Bu maksatla “Arsa ve Arazi Birim Metrekare Değerleri” ve \%1,0 - \%6 arasındaki emlak vergisi artışları, alım-satım vergisi, kentsel arsa ve arazilerdeki değer artışlarına göre çok düşüktür. Bu bağlamda havalimanına ev sahipliği yapan Ordu Gülyalı’da ticari hareketlilik artmış ilçede yapılacak önemli yatırımlar için girişimlerde bulunulmuştur. Ayrıca havalimanına yakın konumda bulunan diğer yerleşim alanlarında da arazi talepleri artmıştır. Havalimanı yurtdışı uçuşlarına açık bir havalimanıdır. Çevre illerdeki havalimanları (özellikle Trabzon havalimanı) incelendiğinde yurtdışından gelen turist sayısı oldukça fazla olduğu görülmektedir. Trabzon'da yabancılara mülk satışı Türkiye'de ilk üç il arasındadır. Bu durum taşınmaz değerinde oldukça önemli bir değişime yol açmaktadır. Ordu - Giresun havalimanının açılması yabancı turist varlığını bu bölgelere doğru yavaş yavaş kaydırmaktadır. Bu durum bölge üzerinde mülkiyet bazlı hızlı bir değişime neden olmaktadır. Şöyle ki, havalimanı çevresindeki taşınmazlarda, 2009-2013 yılları arasında değer takdir komisyonlarınca belirlenmiş değerler yaklaşık \%30 civarında artmıştır. Havalimanının 2011 yılında yapımına başlanması ve 2015 yılında bitirilmesi ile 2013-2017 yılları arasında taşınmazlarda oluşan değer değişimi ise \%100'ü bulmuş ve hatta geçmiştir. Ayrıca günlük alım satım bedelleri incelendiğinde bu değişim \%0400 gibi değerlere ulaşmıştır. Bu bağlamda kamu yatırımı ile oluşan taşınmaz üzerindeki hızlı değer artışı mülkiyet sahiplerini etkilediği kadar, şerefiye uygulamaları gibi kanunlarımıza eklenecek ek maddeler ile kamuyu da olumlu yönde etkilemelidir.

\section{Kaynaklar}

Alonso W. (1964). Location and Land Use: Toward a General Theory of Land Rent. Harvard University Press, Cambridge, MA.

Aslan, M. (2014). Kentsel rantların vergilendirilmesi. Ankara Barosu Dergisi, (3).

Baser, V., Uzun, B., and Yildirim, V. (2019). An alternative method for expropriation for lane-like projects in planned area: a case study from Trabzon in Turkey. Survey Review, 51, 147-153.

Chapman, J.I., G. Cornia, R. Facer, L. Walters. (2009). Alternative Financing Models for Transportation: A Case Study of Land Taxation in Utah, Public Works Management \& Policy, 13(3), 202-214.

Cohen, J.P. (2012). Commentary: Airport Improvement Fees, Benefit Spillovers, and Land Value Capture Mechanisms, in Ingram, G. and Y.H. Hong, eds., Value Capture and Land Policies, Lincoln Institute of Land Policy.

Erdem, N. (2016). Büyük Ölçekli Kamu Yatıımlarının Uygulandığı Bölgelerdeki Taşınmaz Değer Artışı ve Kentleşme Üzerinde Etkisi: Osmaniye İli Örneği. Journal of International Social Research, 9 (47).

Eryılmaz, Y. (2014). Ulaşım Altyapılarının Arazi Değer Artışına Etkileri-Tem Otoyolu İstanbul Anadolu Kesimi Örneği , Doctoral dissertation, İTÜ, Fen Bilimleri Enstitüsü, İstanbul.

Longhofer, S. and C. Redfearn. (2009). Estimating Land Values Using Residential Sales Data. Lincoln Institute of Land Policy Working Paper.

Mills. E. S. (1972). Studies in the Structure of the Urban Economy, Johns Hopkins University Press, Baltimore. Muth R. (1969). Cities and Housing, University of Chicago Press, Chicago, IL. 
Türk H., (2015). Ordu-Giresun Havalimanı (Mekan Seçimi ve Muhtemel Etkileri), Yüksek Lisans Tezi, Giresun Üniversitesi, Sosyal Bilimler Enstitüsü, Giresun.

Trinidad, A. (2017). Impacts of Rail Transit Investments on Demographics and Land Use: 1990-2010, Doctoral dissertation, Clemson University, ABD.

URL 1. http://www.milliyet.com.tr/yabancilara-konut-satisinda-trabzon-trabzon-yerelhaber-2139157/ (Erişim Tarihi: 03.08.2017)

URL 2. https://www.dhmi.gov.tr/Sayfalar/UcusDetay.aspx? $\mathrm{b}=1 \& \mathrm{~s}=0 \& \mathrm{a}=$ trabzon (Erişim Tarihi: 18.08.2017)

Yankaya, U ve Çelik, H. M. (2005). İzmir metrosunun konut fiyatları üzerindeki etkilerinin hedonik fiyat yöntemi ile modellenmesi, D.E.U I.I.I.B.F. Dergisi, 20 (2), 61- 79.

Yankaya, U., ve Çelik, H. M. (2007). Kamu Ulaşım Yatırımlarının Gayrimenkul Değerleri Üzerine Etkisinin Modellenmesi: İzmir Metrosu Örneği. İzmir Yüksek Teknoloji Enstitüsü, Mimarlık Fakültesi, İzmir. 